Vol 11, Issue 8, 2018

\title{
DEVELOPMENT AND EVALUATION OF FLOATING TABLET OF METOPROLOL SUCCINATE FOR INCREASED BIOAVAILABILITY VIA IN VIVO STUDY
}

\author{
KAUSER FATEMA ${ }^{1 *}$, SADHANA SHAHI ${ }^{2}$ \\ ${ }^{1}$ Department of Pharmaceutical Technology, Y.B. Chavan College of Pharmacy, Aurangabad, Maharashtra, India. ${ }^{2}$ Department of \\ Pharmaceutical Technology, Government College of Pharmacy, Aurangabad, Maharashtra, India. Email:Kauserfatema45@gmail.com
}

Reff:https://innovareacademics.in/journals/index.php/ajpcr/article/view/25979/15307

\section{ABSTRACT}

Objective: This study was performed to formulate a floating tablet using hydrophobic glyceryl behenate (GB) and hydrophilic hydroxypropyl methylcellulose polymers, optimization of the same for retention in stomach and sustained drug delivery over a period of $20 \mathrm{~h}$ from upper gastrointestinal tract so as to increase its oral bioavailability.

Methods: Granules of GB with the metoprolol succinate (MS) was formulated and compressed with the other ingredients to formulate a floating tablet. Physiochemical parameters of an optimized formulation along with its in vitro buoyancy study, dissolution study, in vivo studies in rabbit, and stability studies were performed.

Results: Differential scanning calorimetry data show no interaction between polymers and the drug MS. A $3^{2}$ factorial design was applied for optimization purpose, and from ANOVA and surface response plot the best formulation (F3) was obtained. In vitro dissolution study shows sustained drug release for $20 \mathrm{~h}$ for all the formulations and in vivo studies using rabbit model show increased bioavailability of an optimized formulation F3 as compared to the marketed sustained release formulation of MS (25 mg). Stability study shows no comparable differences in physical parameters and the drug release of initial formulation and the one which is kept for accelerated stability testing.

Conclusion: Hence, we can conclude that a floating tablet containing a combination of hydrophilic and hydrophobic polymers can be used for gastric retention for more than $20 \mathrm{~h}$ which will increase the oral bioavailability of MS.

Keywords: Gastroretentive formulation, Metoprolol succinate, Glyceryl behenate, Improved bioavailability.

Erratum of the manuscript no 25979 published in August issue 2018.

\section{OLD AUTHOR'S-}

\section{KAUSER FATEMA1*, SADHANA SHAHI2.}

1Department of Pharmaceutical Technology, Y.B. Chavan College of Pharmacy, Aurangabad, Maharashtra, India. 2Department of Pharmaceutical Technology, Government College of Pharmacy, Aurangabad, Maharashtra.

\section{NEW AUTHOR'S-}

\section{KAUSER FATEMA1*, SADHANA SHAHI2,SYED AYAZ ALI3.}

1Department of Pharmaceutical Technology, Y.B. Chavan College of Pharmacy, Aurangabad, Maharashtra, India. 2Department of Pharmaceutical Technology, Government College of Pharmacy, Aurangabad, Maharashtra.

3Dept. of Pharmacology Y.B.Chavan College of Pharmacy Aurangabad-431001. 